\title{
Erratum to: A Lightweight Network Based on Pyramid Residual Module for Human Pose Estimation
}

\author{
Bingkun Gao ${ }^{a, *}, \mathrm{Ke} \mathrm{Ma}^{a, * *}$, Hongbo $\mathrm{Bi}^{a, * * *}$, and Ling Wang ${ }^{a, * * * *}$ \\ ${ }^{a}$ School of Electrical and Information Engineering, Northeast Petroleum University, Daqing, China \\ *e-mail:bkgao@126.com \\ **e-mail:make098@126.com \\ ***e-mail: bhbdq@126.com \\ ****e-mail: 1024573821@qq.com
}

DOI: $10.1134 / \mathrm{S} 1054661820030049$

The original article can be found online at https://doi.org/10.1134/S1054661819040023

1) Page 668, the corresponding author is Hongbo Bi.

2) Page 669, Fig. 1 should be the follow:

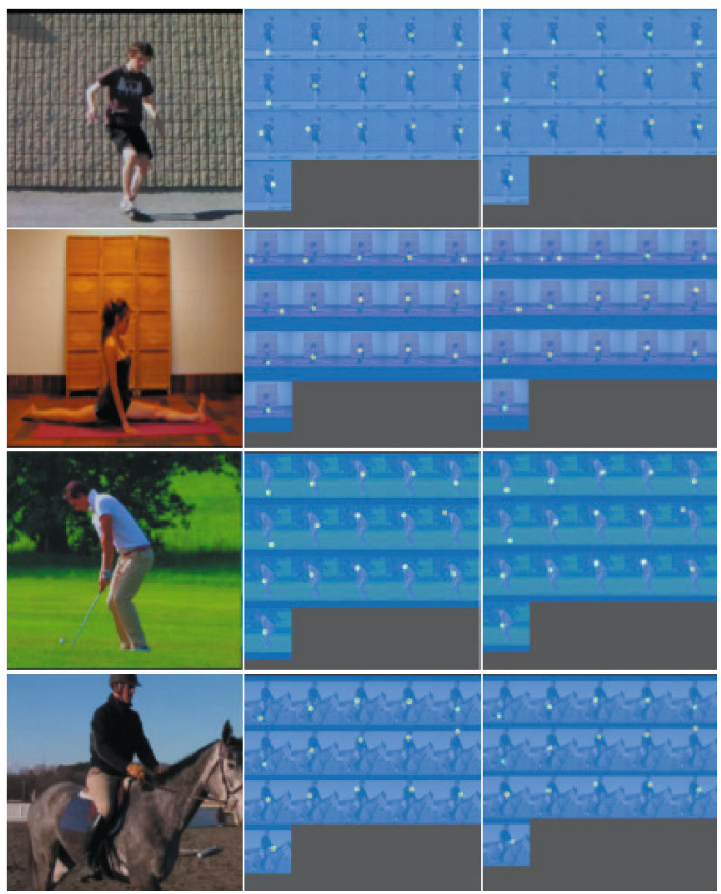

